\title{
Anotações para uma história do mobiliário brasileiro do século XVIII
}

Angela Brandão*

\section{Resumo}

Este texto traz algumas observações acerca do mobiliário do século XVIII, com ênfase no mobiliário mineiro, indicando algumas de suas características formais. Analisa, especialmente, aspectos da historiografia acerca do mobiliário brasileiro.

Palavras-chave: História do mobiliário. Mobiliário - Brasil. Mobiliário do século 18.

\section{Notes for a history of the Brazilian furniture of the 18th century}

\begin{abstract}
This text presents some observations about the furniture of the 18th Century, especially about the furniture of Minas Gerais and its formal characteristics. It analyses aspects of the historiography about the Brazilian furniture.
\end{abstract}

Key-words: History of furniture. Brazilian furniture. Furniture of the $18^{\text {h }}$ century.

\section{Observações sobre o mobiliário do século XVIII}

De um modo geral, o estudo do mobiliário europeu do século XVIII revela um momento de excelência. Os ateliês de fabricação de móveis de luxo, durante o século XVIII, atingiram um alto padrão de elegância e de perfeição técnica. $A$ tipologia dos móveis ampliou-se quantitativamente, adaptados aos mais diversos usos, num processo de enriquecimento dos hábitos domésticos. As funções do mobiliário, neste período, tenderam a uma grande diversificação: mesas de bordar, mesas de jogos, mesas de chá e assim por diante. Pode-se dizer que, embora muitas significações das peças de mobília se tenham transformado, em seu conjunto, o século XVIII apresentou algumas das soluções definitivas, portanto tratase do estudo de um repertório ainda corrente de mobiliário (1). 
Uma das razões que levaram a tais soluções, pode-se dizer, reside no fato de que, pela primeira vez, apresentou-se uma compreensão mais exata das noções de conforto e luxo. O sentimento de conforto, como uma atitude consciente em relação ao corpo e à permissão para relaxar em ocasiões íntimas, como, aliás, a própria noção de intimidade, em detrimento da postura educada, parecem acentuar-se ao longo do Setecentos. Teve-se consciência da rigidez e do desconforto da etiqueta. Afirmaram-se, assim, as noções mais próximas às nossas de privacidade e conforto, assim como a concepção do que deveriam ser ambientes íntimos, em oposição ao espaço público (RYBCZYNSKI, 1999).

Foi, portanto, em torno do estilo a que se denominou rococó que grandes esforços de reformulação de ambientes interiores de casas luxuosas se produziram, assim como uma grande ampliação da produção de conjuntos de mobília, ampliação no sentido quantitativo e qualitativo. Assim, como concepções de "obra de arte total", a arquitetura de interior, os móveis e os objetos de decoração adquiriram um grau de integração como até então não se havia pensado.

Como forma de adaptação ao corpo, os móveis de assento tornaram-se mais baixos e os estofamentos, como uma solução original para a longa história das alfaias, ganharam enorme importância. Móveis se diversificavam, e o incremento de sua produção em manufaturas torná-los-ia acessíveis a um número cada vez maior de pessoas. Surgiu, por outro lado, uma espécie de obsessão pela mobília, encomendada e colecionada com extremo zelo. Os grupos de profissionais que realizavam móveis de luxo: arquitetos, ebanistas e comerciantes de móveis, assim como desenhistas de ornamentos, foram responsáveis, como outros ornamentistas durante o século XVIII, pela publicação de gravuras avulsas ou livros ilustrados de padrões e catálogos de manufaturas. Muitos ateliês agrupavam trabalhos de grupos diferentes de profissionais, ebanistas, estofadores, entalhadores, porcelanistas, reunidos em torno da produção de mobília de luxo e de objetos de decoração. Ateliês como de Thomas Chippendale, na Inglaterra, chegaram a reunir mais de quatrocentos trabalhadores, constituindo verdadeiras manufaturas de artigos de decoração. 
Fundamentalmente um estilo civil de matriz francesa, o rococó viu-se, também no que diz respeito ao mobiliário, adotado pela arquitetura e pela decoração de espaços religiosos, sobretudo ao Sul da Alemanha e em Portugal, assim como no Brasil (OLIVEIRA, 2003, p. 51-74).

Embora no final do século XVIII o mobiliário de estilo rococó começasse a ser visto, pelo viés neoclássico, como extravagância e exagero, permaneceu enraizado no gosto comum como sinônimo de luxo e beleza, mantendo-se como um modelo a ser seguido (RYBCZYNSKI, 1999).

\section{Mobiliário Português e Brasileiro do século XVIII}

A classificação do conjunto do mobiliário no Brasil de período colonial é ainda precária, sendo muitas vezes considerado móvel colonial brasileiro, com difíceis diferenciações, o móvel português trazido para a colônia; o móvel feito em Portugal com madeira brasileira; o móvel feito no Brasil por artífices portugueses; móveis feitos no Brasil por artífices locais, aprendizes de portugueses ou com modelos de móveis portugueses; o móvel feito no Brasil por artífices locais de modo rústico (embora com modelos ainda medievais de tradição popular sempre portuguesa - as mesas de cavalete, a canastra como móvel de guarda e transporte adaptável ao lombo de animais); finalmente, o móvel feito no Brasil por artífices locais ou não, mas com temas decorativos inspirados na flora e fauna nativas.

As casas coloniais de aspecto senhorial, sejam as casas-grandes de fazenda, sejam as assobradadas nos agrupamentos urbanos, foram predominantemente espaços vazios, grandes cômodos desprovidos de mobiliário (VERÍSSIMO, 1999). As funções dos móveis: o sentar-se, o dormir, armazenar, comer, entre outras, foram solucionadas com o uso de bancos toscos de madeira, catres, esteiras e redes, arcas, baús e mesas de cavalete. Embora marcados por inteligentes soluções práticas, estas peças eram desprovidas de maiores intenções estéticas. De outro lado, as funções simbólicas ocuparam grandes esforços em transportar de Portugal ou, por parte de marceneiros, entalhadores e estofadores de oficinas locais em produzir conjuntos inteiros de mobília de luxo (LUCIE-SMITH, 1997). Ainda que no século XVIII houvesse um acréscimo quantitativo e qualitativo de mobiliário no espaço das casas coloniais, foi quase sempre destinada às igrejas a maior parte da 
produção de mobiliário de caráter artístico. Cadeiras com funções honoríficas, bancos e arcazes de sacristias são alguns importantes e numerosos exemplos desse esforço.

Ao lado de uma história do mobiliário do século XVIII como equipamento para a arquitetura civil, abre-se um capítulo sobre peças de mobília referentes ao espaço religioso. Nas igrejas brasileiras setecentistas não existiam bancos para acomodar os fiéis. As celebrações eram assistidas de pé. Uma gravura de Jean-Baptiste Debret, publicada em 1834, demonstra o interior de uma igreja no Rio de Janeiro durante uma liturgia de quarta-feira santa. Mulheres vestidas de negro e com a cabeça coberta por véus distribuíam-se ainda de pé ou sentadas diretamente sobre o chão (DEBRET, 1978, p. 261-264) (2).

Nos inventários das igrejas do século XVIII em Minas Gerais não há referências abundantes à mobília entre os bens pertencentes a cada templo. De um modo geral, são menções pouco numerosas e bastante restritas do ponto de vista descritivo. Percebe-se que as igrejas, em sua maioria, possuíam poucas peças de mobília e, naturalmente, catedrais contavam com um número maior de peças. No entanto, do ponto de vista dos inventários, tinha-se claro que os móveis deveriam constar entre os bens da igreja e que havia uma distinção entre móveis de luxo, como uma cadeira episcopal, uma mesa torneada, uma cadeira estofada, via de regra, em jacarandá; e, por outro lado, móveis mais simples como tamboretes, bancos, armários - muitas vezes descritos como "de pau branco". Provavelmente era uma forma de distingui-los dos móveis escuros de jacarandá (3).

Entre as igrejas do contexto mineiro, assim como de um modo abrangente nas igrejas brasileiras do período colonial, as peças de mobília que constavam nos templos consistiam, em geral, em poucos bancos ou tamboretes usados na capela mor como apoio para os participantes da liturgia (FIGURA 01); alguns bancos mais simples dispostos em corredores de acesso às sacristias, em grandes mesas com ou sem gavetas nas sacristias para estender e passar os paramentos e nos imponentes arcazes (FIGURA 02). Sobre estes, Robert Smith escreveu: 
De todas as formas de mobiliário que os portugueses trouxeram para sua primitiva colônia do Brasil, nenhuma foi tão original em concepção, mais perfeita em execução ou variada em interpretação do que o armário ou guarda-roupa de sacristia. (SMITH, 1979, p. 329)

Do maneirismo ao barroco nacional português e joanino, ao rococó Dom José I, as variações estilísticas acompanharam a concepção desse pequeno conjunto de mobília que caberia a cada igreja. Nota-se, no entanto, em inventários de capelas menores e mais afastadas, a ausência completa de qualquer referência a peças de mobília.

No que se refere ao móvel brasileiro específico do século XVIII, agrupou-se estilisticamente o que foi produzido na primeira metade do século em torno da denominação $\mathrm{D}$. João $\mathrm{V}$ ou joanino, adotando a nomenclatura aplicada também à talha e aos retábulos correspondentes aos anos do mesmo reinado: 1706-1759.

Em sua primeira fase, o estilo joanino, quanto ao mobiliário, manteve os elementos do período anterior, denominado por Robert Smith de "nacional português", do XVII, de móveis severos, retos e sólidos. Em sua segunda fase, as linhas barrocas apresentaram-se de modo mais claro no mobiliário português: as pernas curvas em cabriolê de saída brusca, por influência inglesa (dos estilos Rainha Ana e georgiano), a presença de pés de garra e bola, elementos decorativos entalhados, como folhas de acanto e conchas nos espaldares dos móveis de assento, nas joelheiras e saias. A talha sobre o móvel deste período mostrou-se profunda, cheia e em profusão, obscurecendo os torneados e goivados do estilo anterior, ainda marcado pelo nacional-português. $O$ encosto dos móveis de assento começou a apresentar-se vazado, com uma tabela ao centro. A cadeira de sola, de couro lavrado, permaneceu no repertório do mobiliário luso-brasileiro, adaptando-se às formas do barroco e, mais tarde, do rococó (FIGURA 03) (CANTI, 1980).

Justamente, a terceira fase do estilo joanino indicou a transição do barroco ao rococó, no que se refere à mobília. Surgiram as cadeiras com assento de palhinha, encostos vazados com tabela central em forma de violão e entalhes em forma de um feixe de plumas no alto do espaldar, tanto das cadeiras como das camas. As 
cômodas passaram a adotar linhas curvas em seu corpo mesmo. Imprimiam-se, sobre os móveis de um modo geral, alguns elementos de chinoiserie.

Foi, portanto, das características de transição do terceiro e último período do estilo joanino que se apresentaram novas formas na mobília, como na talha em geral e nas grandes composições dos retábulos, o rococó português que se convencionou chamar de estilo D. José I, cujo reinado se estendeu entre 1750 e 1777.

O estilo D. José I, no âmbito da mobília portuguesa, segue a última fase do D. João $V$, sofrendo influência do rococó francês, com a adoção definitiva de rocalhas. Fundiram-se às influências francesas as formas inglesas de derivação rococó, o estilo Chippendale, associadas a elementos tipicamente portugueses. A talha tornava-se, agora, menos profunda e reservada a alguns pontos da peça, em contraste com o aspecto liso e vazio de partes inteiras; desapareciam as amarrações das travas das pernas da mobília, que ganhava agora pernas inteiriças em suave cabriolê, dotadas de um aspecto esguio e de joelheiras pouco acentuadas. Surge uma grande variedade de cadeiras, de espaldares mais baixos e largos, de assentos mais baixos e, ainda, as cadeiras de canto (FIGURA 04) (CANTI, 1980).

As cômodas ganhavam formas abauladas na parte da frente, com saliências e reentrâncias. Diversificou-se o uso dos móveis de guarda, e derivaram das cômodas móveis destinados a abrigar a estatuária de devoção doméstica, as chamadas "cômodas-oratório". No lugar das camas de galeria ou de bilros, de influência indiana, que haviam sido considerados como designação de luxo e poder pelos domínios portugueses, surgiram leitos não menos luxuosos com colunas esguias, estriadas e em leve espiral, rematadas por pináculos. Suas cabeceiras recortadas e vazadas passavam a ser decoradas com volutas, conchas, rocalhas, palmas e flores entalhadas em madeira, com medalhões almofadados, estofados com seda, ao centro (CANTI, 1980).

Embora ainda houvesse transposição de peças de mobiliário da metrópole à colônia, o Brasil do século XVIII já contava, certamente, com uma importante produção de mobília, não apenas de aspecto tosco, destinada ao uso cotidiano, mas também 
aquela de caráter simbólico, associada ao luxo e à ostentação. Robert Smith salientou a importância e a qualidade artística do mobiliário produzido no período colonial brasileiro (SMITH, 1979). Entre os importantes centros de produção de móveis, a Bahia tornara-se grande produtora de cadeiras, que reproduziam modelos ingleses do século XVIII: introdução da influência dos modelos dos famosos ebanistas, como Thomas Chippendale, George Happlewhite e Thomas Sheraton. Vale lembrar que estas três importantes referências, em termos de produção e exportação de peças e de formas de mobília para o século XVIII luso-brasileiro, foram também responsáveis por publicações ilustradas com gravuras de completo repertório de móveis.

A influência de Sheraton se difundiu de tal forma entre marceneiros atuantes no Brasil, sobretudo no contexto de Minas Gerais, que passaram a adotar a simplicidade, as linhas retas do estilo, onde a madeira não se apresentava mais camuflada pelos entalhes, mas ela mesma em tons claros e escuros, tomando como elemento decorativo simplesmente o contraste de cores de madeira, em forma de incrustações. Dessa adaptação convencionou-se tratar de um estilo Sheraton Brasileiro. (FIGURA 05) (CANTI, 1980)

Nas últimas décadas do século XVIII, o mobiliário português, e por extensão o móvel brasileiro, submeteu-se a variações, que sugerem a transição do rococó ao neoclassicismo, cujo nome adotado foi estilo D. Maria I (1777-1792). Na mobília chamada de D. Maria I, ao lado do rococó, formas mais sóbrias se delinearam. As pernas dos móveis ganharam um corte circular, ou seja, tornaram-se cilíndricas com estrias, como colunetas, desaparecendo, assim, o cabriolê. Os novos elementos decorativos adotados foram os fios de pérola, os festões de flores, como, aliás, flores miúdas e laços de fita, entalhados em madeira e vazados. De um modo geral, os móveis passaram a apresentar corpos mais retangulares, no lugar da talha compunham-se incrustações de madeira clara, em filetes, sobre superfícies lisas. Diminuem ou desaparecem completamente os entalhes; e a decoração com incrustações de madeira ou madrepérolas predomina (CANTI, 1980).

As camas, consideradas as peças mais interessantes no estilo, têm pés retos e finos; cabeceiras ovais ou hexagonais com pinturas ou tecidos, decoradas ainda 
com desenhos incrustados ou por uma talha rasa com motivos característicos dos laços de fitas, correntes de pérolas, festões de flores miúdas.

Conclui-se que o século XVIII brasileiro representou um período de importante produção artesanal de mobília e que tal produção evoca não apenas elementos de sua integração com a arquitetura civil e religiosa, mas também o diálogo com a escultura, sobretudo com o repertório da talha.

\section{Mobiliário brasileiro, uma abordagem historiográfica}

No Brasil, os estudos históricos em torno da mobília aparecem apenas no século XX. No entanto, percebe-se um importante interesse, por parte de diversos autores da literatura brasileira do século anterior, em descrever as casas, seus objetos, sua decoração - especialmente do romantismo ao realismo. Os móveis apareciam, aqui, sob diferentes aspectos, como cenários para a existência dos personagens.

Se levarmos em conta que a criação do Serviço de Patrimônio Histórico e Artístico Nacional datava de 1937, o estudo histórico do móvel brasileiro não pareceria, enfim, tão tardio. Em realidade, a existência de um órgão oficial destinado ao estudo e programas de preservação dos bens culturais no Brasil abria o caminho para o início de uma historiografia do mobiliário brasileiro. De fato, alguns estudos vieram à luz na Revista do IPHAN. Desde o primeiro número da revista, em 1937, publicarase o texto "Mobiliário Nacional". Sucederam-se o artigo de Clado Ribeiro de Lessa, publicado em 1939, na Revista Estudos Brasileiros; e já nos anos 1940, os estudos de José de Almeida Santos e de Gustavo Barroso (4).

Por outro caminho, no entanto, Gilberto Freyre percebia, desde 1931, que certas peças da mobília faziam parte da compreensão da cultura brasileira. Os bancos de varanda eram, para ele, referências à cordialidade e hospitalidade da casa-grande, ao mesmo tempo garantidores do conservadorismo e da preservação da intimidade da família, ao passo em que compunham o espaço de transição entre o público e o privado - a varanda (FREYRE, 1987, p. 41-89). Da mesma forma, a rede aparece nas notas de "Casa Grande \& Senzala" como a "cama brasileira", associada a um amplo significado como lugar do pecado; (5) como berço dos indígenas; como 
transporte de mortos e feridos; como manifestação do gosto pelo repouso combinado ao prazer do movimento (FREYRE, p. 204-207).

À rede, o folclorista Luís Câmara Cascudo dedicaria todo um livro, "Rede de Dormir", um fascinante compêndio de diversos documentos, canções, poemas e referências dedicadas à "cama brasileira" (CASCUDO, 2003).

O texto de Lúcio Costa, porém, "Notas sobre a evolução do mobiliário lusobrasileiro", de 1939, constituiu um entre os primeiros estudos com intenções de organizar, de modo geral, todo o percurso histórico do mobiliário luso-brasileiro (COSTA, 2000, p. 195-206). O artigo fora escrito como introdução para um álbum de fotografias de móveis brasileiros, destinado à Feira Internacional de Nova York, nunca impresso. Foi, no entanto, publicado na Revista de número três, do Serviço do Patrimônio Histórico e Artístico Nacional. Entre as primeiras linhas, o autor reconhecia o ineditismo do estudo que ora apresentava:

As diferenciações que o estudo mais demorado da matéria poderá revelar [..] só agora aqui iniciado pelo Serviço do Patrimônio Histórico e Artístico Nacional, com o inventário sistemático das peças ainda existentes nas várias regiões do país [...] (COSTA, 2000, p. 194).

Em suas "Notas", cujo título indicava mesmo um estudo apenas esboçado, Lúcio Costa atinha-se muito brevemente, mas sempre com precisão, a cada período do mobiliário luso-brasileiro, compreendendo seus componentes de raiz portuguesa e o amálgama de influências européias, mouras e indianas; reservando para estudos posteriores o problema da identificação do móvel brasileiro com características próprias (COSTA, 2000, p. 195-196). Não adotava, para tanto, uma classificação estilística baseada na sucessão do gosto dos monarcas portugueses, nem mesmo exatamente critérios estilísticos tomados da história da arte. Dividiu, assim, a história do móvel brasileiro em três grandes períodos. O primeiro corresponderia aos séculos XVI e XVII e início do XVIII; o segundo, barroco, ocuparia o século XVIII como um todo; enquanto o terceiro período caberia a uma "reação acadêmica" desde finais do XVIII à primeira metade do XIX. Para o arquiteto, depois disso, o móvel brasileiro teria caído num universo de "modas improvisadas e sem rumo, já desorientadas pela produção industrial" (COSTA, 2000, p. 197-198). 
Tais palavras indicavam claramente as idéias do arquiteto moderno que, por um lado excluía, curiosamente, o móvel moderno de uma história do mobiliário e, por outro, dentro dos limites de seu olhar, desdenhava o caráter eclético e revivalista da mobília da segunda metade do século XIX, tão desprezado também por ele nas obras arquitetônicas.

Além da conhecida síntese de história do mobiliário luso-brasileiro formulada por Lúcio Costa na Revista do Instituto de Patrimônio Histórico e Artístico Nacional de número três, de 1939, neste mesmo número Hélcia Dias publicava o texto: "Mobiliário dos Inconfidentes". Iniciava com a seguinte problemática:

São muito poucas e esparsas as referências bibliográficas ao mobiliário antigo no Brasil.[...] Nos cronistas, as referências são na maioria das vezes insuficientes, limitando-se à descrição minuciosa das nossas madeiras e à notícia de seu aproveitamento na fabricação de móveis. [...] Quanto aos viajantes, esses pouco mais se estendem sobre o assunto. [...]. (DIAS, 1939, p. 163).

E a autora concluía, em seguida:

Diante da deficiência desses elementos, parece mais acertado para o estudo do mobiliário brasileiro a consulta dos manuscritos antigos: testamentos, inventários, autos de arrematação, etc. Esses subsídios, que se encontram em arquivos eclesiásticos e civis de todo o Brasil, são, porém de acesso difícil. Assim, a publicação dos Autos de Devassa da Inconfidência Mineira, feita por iniciativa do Ministério de Educação e Saúde, ofereceu excelente oportunidade para se tentar, pelo menos, um estudo relativo ao mobiliário usado em Minas Gerais em fins do século XVIII. (DIAS, 1939, p. 164).

A autora tratava comparativamente as menções em torno do mobiliário presentes na publicação dos Autos da Devassa dos Inconfidentes e o livro de Alcântara Machado "Vida e Morte de Bandeirante", baseado este nos inventários de 1578 a 1700 processados em São Paulo como "base interessante para a comparação do mobiliário e de outros aspectos do meio paulista daquele período com o mineiro, de mais de um século depois". Concluiria que

[...] foi grande a melhoria de situação dos mineradores em relação a dos primeiros bandeirantes de São Paulo. No que diz respeito ao mobiliário, porém a apreciação é menos 
otimista, embora se possa notar alguma diferença quanto ao número, quanto à qualidade $\mathrm{e}$ mesmo quanto à variedade de espécies. (DIAS, 1939, p. 165).

Embora tivesse mencionado em sua bibliografia o livro de Gilberto Freyre, "Casa Grande \& Senzala", foi por um viés diferente que José de Almeida Santos concebeu seu estudo "Mobiliário Artístico Brasileiro", publicado em 1944. Em três tomos, o primeiro apresentava propriamente uma história do móvel no Brasil; o segundo e o terceiro tomos compunham um dicionário de termos ebanísticos. O livro resultava de viagens realizadas por todo o país, do Rio Grande do Sul ao Nordeste, como afirmava o autor, de visitas a museus, igrejas e coleções particulares, e de uma série de leituras de documentos, inclusive de textos literários. Escrito entre 1942 e 1943, "Mobiliário Artístico" abria uma ardorosa discussão em torno da identidade do mobiliário brasileiro, em oposição à simples cópia dos modelos portugueses, buscando localizar entre o estilo colonial, D. Maria I e D. João VI (este dois, aliás, considerava-os em conjunto) e a obra de Béranger (6) como manifestações únicas do mobiliário exclusivamente brasileiro, sem correspondência européia (SANTOS, 1944, p. 1-34).

Apesar de alguns equívocos, como o de considerar idênticos os estilos Dona Maria I e D. João $\mathrm{VI}$ ou de praticamente desconsiderar o nome de Julien Béranger, reconhecendo apenas o trabalho de seu filho Francisco Manuel Béranger, entre outros, o livro de José de Almeida Santos apresentava uma importante contribuição no prosseguimento dos estudos acerca da história do mobiliário brasileiro. Dividia seu trabalho em quatro partes. A primeira dedicada aos séculos XVII e XVIII e também ao estilo Sheraton. A segunda parte concentrada no século XIX, de D. Maria I, estilo por ele considerado brasileiro, de Béranger ao panorama atual. A terceira parte compunha-se de um estudo tipológico sobre peças do mobiliário brasileiro como as banquetas e uma certa high boy brasileira. A quarta parte, enfim, retomava discussões estilísticas anteriores e propunha ainda curiosas sugestões sobre o móvel moderno brasileiro e sobre a ocupação da "casa mínima".

José de Almeida Santos discutia criticamente o mobiliário brasileiro, situava-o, em alguns momentos, numa discussão não meramente formal, mas contextual, apontando problemas de interpretação, acusando lacunas e, mais uma vez, a falta 
de estudos sobre o mobiliário brasileiro, assim como a necessidade de criação de museus dedicados ao tema.

Foi, no entanto, entre o final dos anos 1940 e o início da década de 1950 que surgiu o projeto de publicação de uma obra completa dedicada à história da arte brasileira. A coleção seria composta de vários volumes com o apoio de duas instituições financeiras. Dirigido por Rodrigo Melo Franco de Andrade, o projeto não foi nunca finalizado, tendo sido publicado apenas o primeiro volume. Nesta obra, um dos capítulos era dedicado, justamente, ao mobiliário brasileiro. Seu autor era José Washt Rodrigues.

José Wasth Rodrigues, como pintor de temas históricos, foi membro da Secretaria de Patrimônio Histórico e Artístico Nacional e dedicou-se ao estudo e registro de paisagens históricas brasileiras, que aparecem tanto em suas ilustrações científicas quanto em suas obras de pintura. Foi um dos primeiros a estudar, sistematicamente, a história da indumentária, com publicações sobre trajes civis e militares: Fardas do Reino Unido e do Império, Trajes civis e militares do Brasil durante o domínio holandês e Tropas paulistas de outrora (PONTUAL, 1969).

Porém, talvez tenha sido sua obra mais importante o Documentário Arquitetônico: relativo à antiga construção civil no Brasil, cuja primeira edição foi publicada em fascículos em 1944. Feito a partir de anotações de viagens e de fotografias reunidas desde sua primeira estadia nas cidades históricas de Minas Gerais, em 1918, o livro registrava minuciosamente os elementos do passado: chafarizes, grades, luminárias, bandeiras de janelas, sacadas, cornijas, até os espelhos das fechaduras, os sistemas dos trincos e o funcionamento das fechaduras de portas. Seus desenhos são tomados por uma obsessão em dissecar os detalhes do passado, minuciosamente, com suas medidas e escalas, como numa lição de anatomia. $O$ esforço detalhista e documental de Wasth Rodrigues parece querer não apenas conservar o passado, mas refazê-lo através do desenho (RODRIGUES, 1975).

Esse livro consistia, portanto, num inventário minucioso da arquitetura colonial na região de Minas Gerais, sobretudo em torno das cidades de Ouro Preto e Mariana. Wasth Rodrigues, depois de viajar detidamente por aquelas cidades, reconstituiu em 
desenhos o aspecto original dos edifícios e de certos aspectos urbanísticos, comparando-os com seu aspecto então atual. Dedicou-se a registrar os detalhes, como fechaduras de portas e ferragens de janelas, num esforço comparável ao de um colecionador de borboletas. O passado, em sua materialidade, era dissecado cientificamente por Wasth Rodrigues.

A observação de Wasth Rodrigues seria, portanto, a de um estudioso da arquitetura colonial, com o mesmo detalhismo com que se dedicou ao estudo das fardas do Reino Unido e do Império, dos uniformes do exército à heráldica, com o mesmo detalhismo com que se dedicará ao estudo do mobiliário.

Na introdução geral da coleção, onde se inseriu o capítulo sobre mobiliário de Wasth Rodrigues, Rodrigo Melo Franco de Andrade indicava que enquanto alguns aspectos do patrimônio artístico nacional eram alvo de estudos sucessivos, outros continuavam "descurados e desconhecidos por completo, à espera da atenção dos investigadores" (ANDRADE, apud RODRIGUES, 1975, p. 12). Assim, também, considerava fundamental o inventário das obras produzidas no Brasil, pois a partir deste "domínio das obras" seria possível investigá-las. Era talvez, entre outras obras, o mobiliário brasileiro um dos aspectos do patrimônio ainda merecedor de esforço de levantamento.

Da mesma forma, em sua introdução, José Wasth Rodrigues, insistia sobre o problema da falta de estudos acerca do mobiliário brasileiro: "É necessário estudarse o tema - mobiliário luso-brasileiro - buscando suas raízes ou origens e suas razões históricas, em método científico [...]”. E, mais adiante:

\footnotetext{
A falta de melhor divulgação e de estudos metódicos sobre nosso mobiliário tem, como resultado, o completo alheamento e desconhecimento de seus característicos por parte de autores estrangeiros [...]. (RODRIGUES, 1968, p. 16).
}

A história do mobiliário brasileiro de Wasth Rodrigues dividia-se em três partes desiguais. A primeira tratava das peças anteriores ao século XVIII, agrupadas de modo tipológico (armários, mesas, etc.). A segunda e mais importante parte, à qual o autor dedicou seus maiores esforços, abordava o móvel brasileiro do século XVIII, 
dividido entre os estilos D. João V, D. José I e D. Maria I. A última pequena parte tratava do móvel do século XIX, sob os estilos Império e Restauração. Quanto a esta última abordagem, ficava, pela primeira vez e definitivamente, esclarecida a diferença entre os estilos D. Maria I e D. João VI, antes apresentados como um mesmo estilo por Almeida Santos.

A apresentação do móvel brasileiro, na obra de Rodrigues, estabelecia, também por primeira vez, a combinação entre dois critérios de abordagem. Este recurso metodológico solucionava, aparentemente, o complexo emaranhado do estudo das formas. Combinava um sistema de estudo cronológico (séculos XVI-XVII, século XVIII e século XIX) a um tratamento estilístico (filiando-se à convenção de denominar os estilos com uso dos nomes dos monarcas portugueses). E, mais importante, acrescentava ao estudo cronológico-estilístico uma divisão tipológica da mobília (mesas, cadeiras, etc.). Esse critério parece ter sido adotado em vários estudos que se seguiram no século $X X$ sobre o mobiliário brasileiro, tanto em produções historiográficas quanto em catalogações de museus.

O aprofundamento no mundo das formas pelo olhar cuidadoso de Wasth Rodrigues levou-o a considerar que a mobília resultava de uma complexa combinação de formas, as quais apenas a cronologia e o estilo seriam insuficientes para elucidar. Cruzava, assim, informações por categorias de tempo, de denominações de estilos por nomes de monarcas às influências inglesas, francesas, estilísticas propriamente, como barroco e rococó e a tipologia da mobília (RODRIGUES, 1968, p. 106).

Longe de adotar uma solução simplista, o autor propunha a difícil tarefa de reconhecimento dos objetos do passado, traçando uma rede complexa de influências e de permanências. Assim, em sua origem portuguesa, a mobília brasileira resultava da combinação de diversas matrizes culturais, orientais, medioorientais e européias. Reconhecia como problema para uma precisa delimitação cronológica dos móveis, a permanência e a sobreposição de características, traindo de modo coerente, a noção rígida de estilo. Num determinado ponto de seu estudo, admitia a questão: "Esta peça, como algumas outras, pelo seu estilo definido, passa para o século XVIII, conservando a mesma composição e ornamentação, o que 
dificulta clareza de época, e do que resultam equívocos [...]" (ANDRADE, 1968, não paginado).

Por outro lado, uma das principais preocupações de José Wasth Rodrigues era, justamente, uma apreciação detalhada e a definitiva diferenciação entre os dois principais estilos do século XVIII no mobiliário luso-brasileiro, D. João V e D. José I. Em suas palavras:

[...] não existe diferenciação bastante nos móveis produzidos no reinado de D. João $\mathrm{V}$, em relação aos produzidos no de D. José I, que permita classificá-los distintamente? Sim. E essa diferenciação é tão grande que não se justifica mais o uso de expressões vagas e acomodatícias para distingui-la. (RODRIGUES, p. 24).

Estabelecia regras formais para identificá-los, compreendendo, no entanto, a transição e as sobreposições entre um período e outro.

Uma de suas intenções era, certamente, dar ênfase e valorizar os móveis produzidos sob o período de D. José I, associados de modo geral ao rococó:

[...] peculiaridade dos móveis deste feliz momento é a perfeição técnica com que são realizados seus movimentos e baixo-relevos; perfeição que nos produz uma satisfação indefinível, levando-nos pelo tato a sentir seu mórbido encanto. (RODRIGUES, 1968, p. 79).

Ao observar e estilo no mobiliário D. José I e suas características formais, Wasth Rodrigues estabelecia, porém, uma ampliação importante na compreensão histórica da correlação entre artes aplicadas, os efeitos decorativos na mobília, e a escultura e os trabalhos em talha na decoração interna da arquitetura religiosa. Para ele, Antônio Francisco Lisboa, o Aleijadinho

não só sentiu e interpretou o estilo D. José I, como criou - em suas portadas, lavabos e púlpitos - obras singulares, nas quais exalta e domina o estilo com a segurança de mestre insuperado (RODRIGUES, 1968, p. 76).

Era talvez inédita essa compreensão do mobiliário como parte da criação artística de um período da história da arte brasileira. Assim, muitos de seus estudos dos ornatos presentes na talha dos móveis, apareciam acompanhados de exemplos de detalhes 
das obras de Aleijadinho, propondo definitivamente a relação entre mobiliário e escultura em madeira e pedra (FIGURA 06) (RODRIGUES, 1968, p. 81).

O grande esforço de José Wasth Rodrigues, em sua história do mobiliário brasileiro, era estabelecer critérios formais para compreensão visual e identificação dos estilos apresentados. Para tanto, seu texto detém-se com rigor em detalhadas descrições formais da peças de trastaria. Quando não bastassem as palavras, ali estava o desenho e o desmembramento das partes para não restar dúvidas no reconhecimento da peça. Wasth Rodrigues propunha-nos, assim, um guia para o olhar.

O estudo dos ornatos, como vimos, parecia, portanto, fundamental. Era nos detalhes da mobília que se podia encontrar sua situação histórica. Nas pranchas, cuidadosamente desenhadas pelo autor, acumulavam-se detalhes formais e fragmentos de entalhes. Da mesma maneira, preocupava-se em esclarecer problemas construtivos, madeiras utilizadas, sistemas de encaixes e montagem, uso de materiais como colas, etc.

Como não poderia deixar de ser, o livro "Mobiliário" de José Wasth Rodrigues partia da observação direta das obras. Assim como em seu "Documentário Arquitetônico" de 1950, o "Mobiliário" resultava da consulta de acervos, no entanto, estes especialmente situados em São Paulo e Rio de Janeiro, entre coleções particulares e museus. Assim, a fonte principal da pesquisa histórica de Wasth Rodrigues era o mobiliário propriamente, sendo raras as ampliações das fontes para outras espécies de documentação.

A contribuição metodológica para o estudo histórico do móvel brasileiro de José Wasth Rodrigues foi, sob diferentes aspectos, fundamental. Precisamente por seu esforço científico em descrever e reconhecer, datar e agrupar, com diferentes métodos o conjunto do acervo que pretendia analisar, foi capaz de traçar objetivamente a organização do estudo histórico do mobiliário, sem obscurecer, no entanto, a complexidade de combinações de estilos e suas procedências, as limitações mesmo das classificações dos objetos artísticos. 
É possível encontrar traços dessa organização metodológica até mesmo nos estudos elaborados por Tilde Canti, já nos anos 1980, "O Móvel do Século XIX no Brasil" ou em "O Móvel no Brasil: Origens, Evolução e Características"; e ainda nas publicações do Museu da Casa Brasileira. Nos anos 1990, Maria Cecília Loschiavo dos Santos debruçou-se, pela primeira vez, sobre o móvel moderno no Brasil, iniciando um capítulo definitivo da história do mobiliário brasileiro (SANTOS, 1995).

Por outro caminho, o historiador da arte norte-americano, estudioso do Setecentos luso-brasileiro, Robert Smith, desenvolvia nos anos 1970 trabalhos como "José Gomes de Figueiredo e o seu Mobiliário Pernambucano do século XVIII", publicado no The Connoisseur em 1972. Nesse estudo concluía que no Brasil "a fabricação de mobiliário atingiu um grande desenvolvimento mais elevado do que em qualquer outra parte da América Latina, durante a segunda metade do século XVIII". Indicava, então, aos pesquisadores brasileiros, importantes caminhos de estudo de atribuição de autoria a partir de observações formalistas e de levantamento de documentação. (SMITH, 1979, p. 330).

A descrição, identificação, datação e catalogação dos acervos históricos brasileiros foram, no entanto, entendidas, muitas vezes, como esforços mais próprios de arquivistas e museólogos e menos como um esforço próprio do historiador. Abordagens mais formalistas seriam, portanto, "menores" se comparados às ampliações de caráter contextual e sociológico. Mas era, talvez, a partir da tarefa de autores como Robert Smith e José Wasth Rodrigues, que se construía aquele "domínio das obras" que Rodrigo Melo Franco de Andrade reclamava na introdução da coleção inconclusa de história geral da arte brasileira.

Resta, portanto, ainda por estabelecer-se um estudo mais amplo sobre o universo da produção de mobiliário por grupos anônimos de marceneiros e suas relações com as outras artes atuantes nos canteiros das grandes obras arquitetônicas do período colonial; assim também estabelecer as relações entre mobiliário artístico e outras peças de escultura como oratórios, os tronos em miniatura que aparecem nas representações de Santana Mestra (FIGURA 07) e tantos outros elementos formais em diversas obras escultóricas de caráter monumental. 


\section{Imagens}

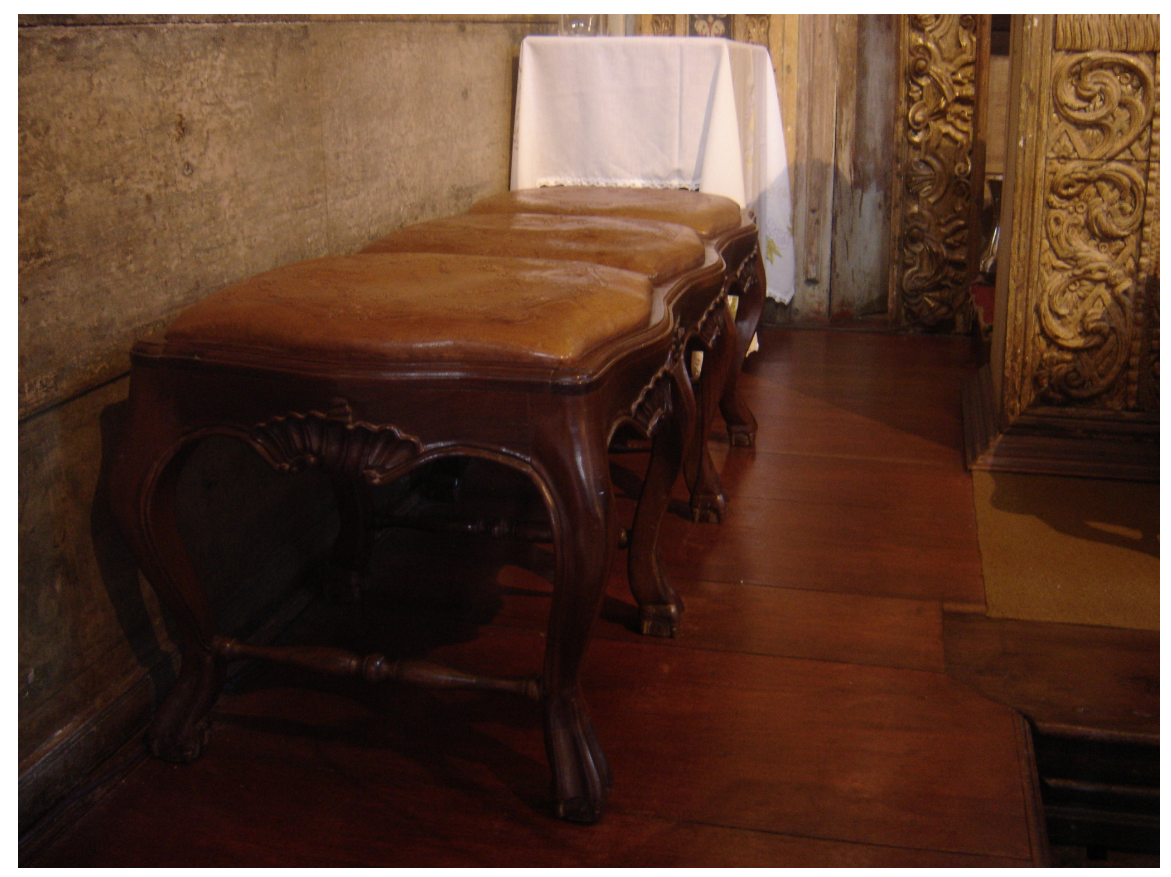

FIGURA 01 - Banco do

Altar Mor da Capela do

Padre Faria, primeira

metade do século XVIII.

Jacarandá e couro. Ouro

Preto. Fotografia da

autora.

FIGURA 02 - Oratório (atribuído a Antônio Francisco Lisboa), arcaz e detalhe da mesa da Sacristia da Matriz de Nossa Senhora do Pilar. Ouro Preto. Fotografia da autora.

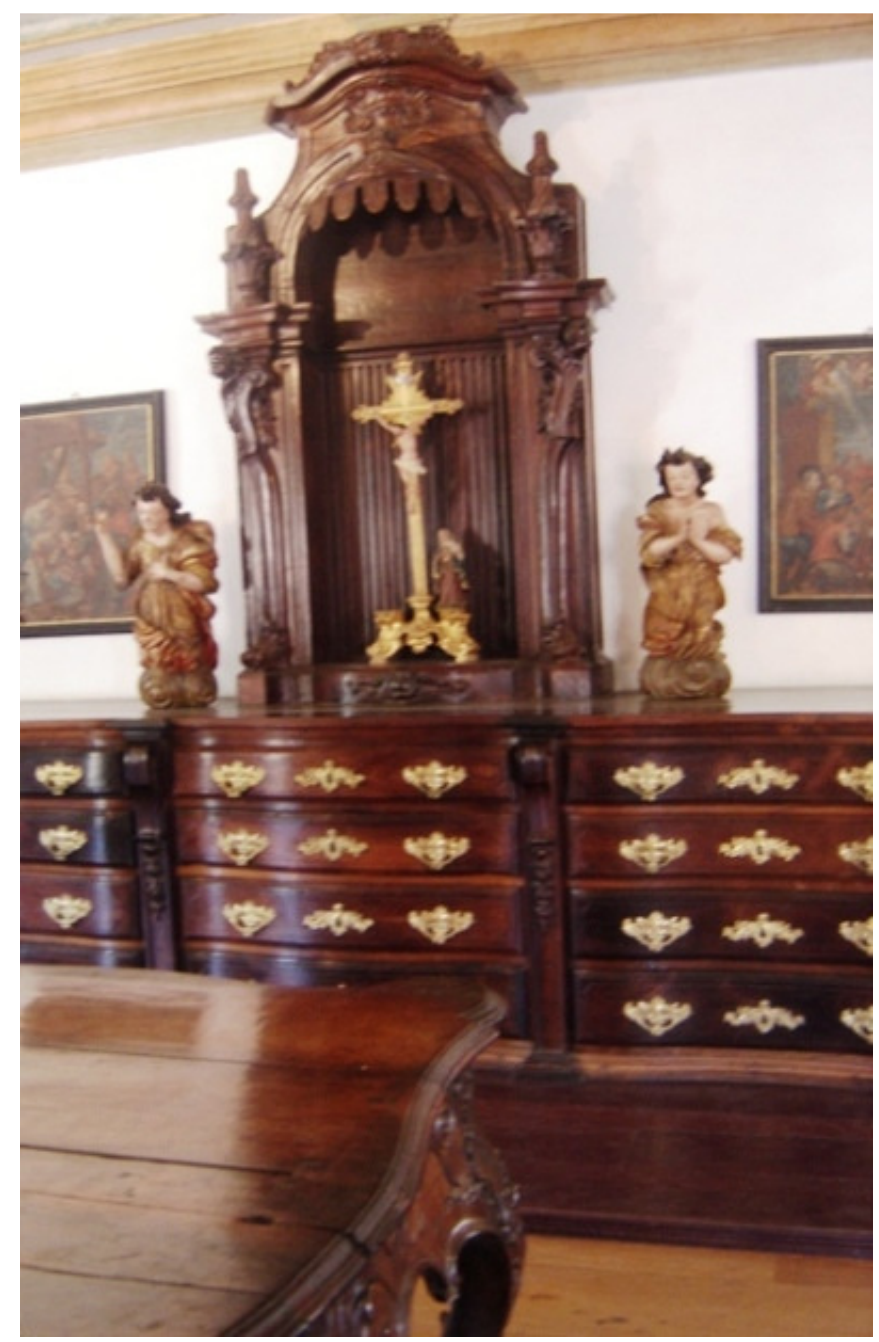




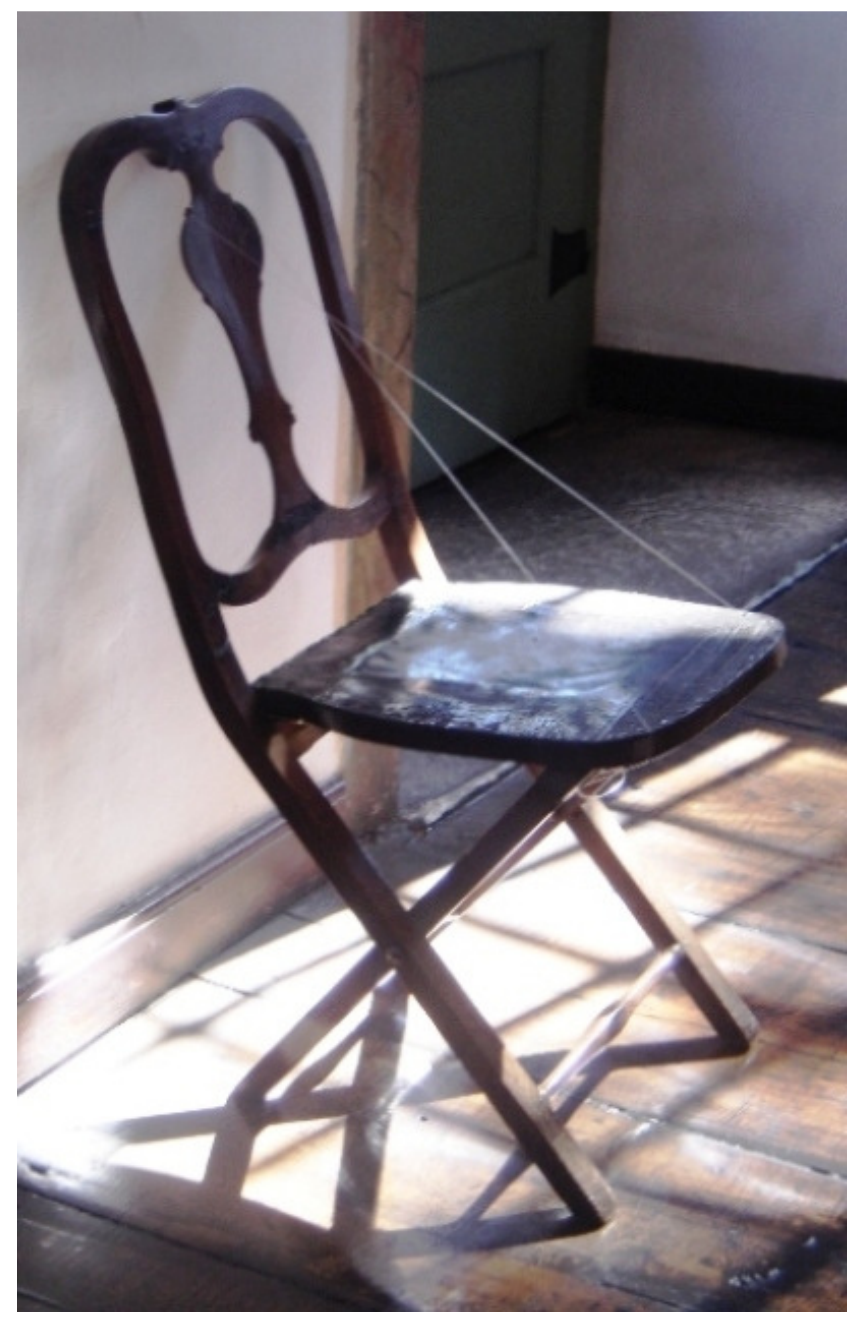

FIGURA 03 - Exemplo de Cadeira de Sola de Campanha. Século XVIII. Casa dos Contos, Ouro Preto. Fotografia da autora.

FIGURA 04 - Trono Episcopal e cadeiras (atribuídos a Antônio Francisco Lisboa). Jacarandá entalhado e estofado. c. 1778-1783 proveniente do Paço Episcopal de Mariana. Museu Arquidiocesano de Arte Sacra de Mariana. Fotografia da autora.

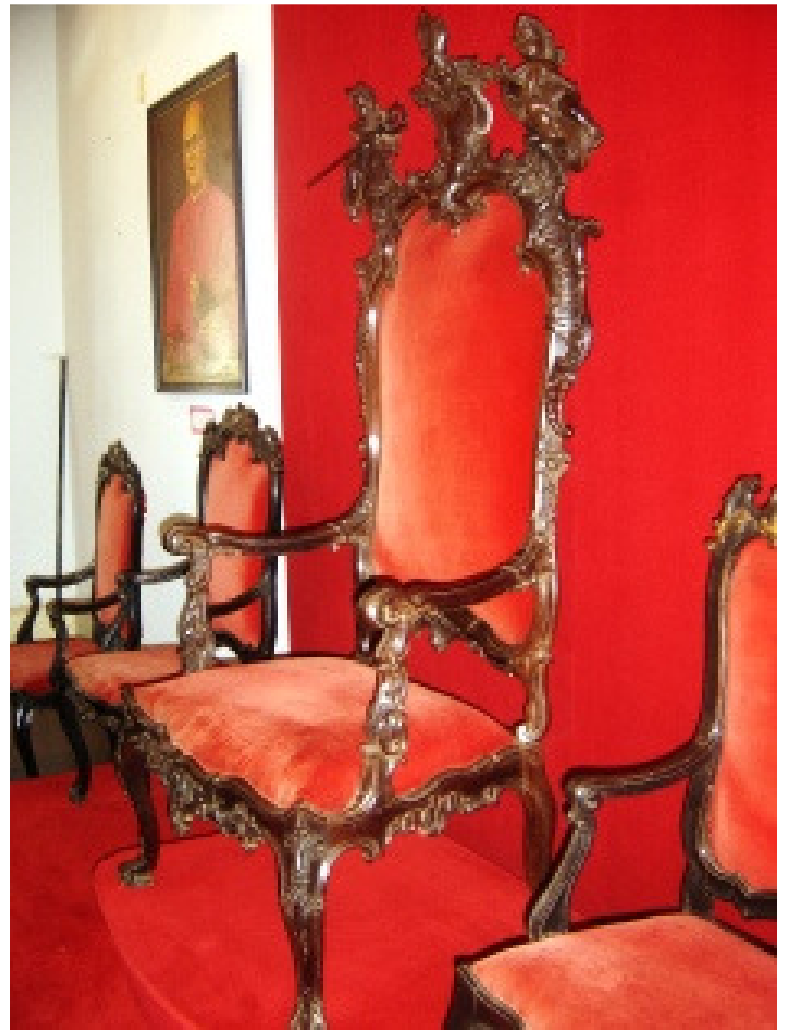




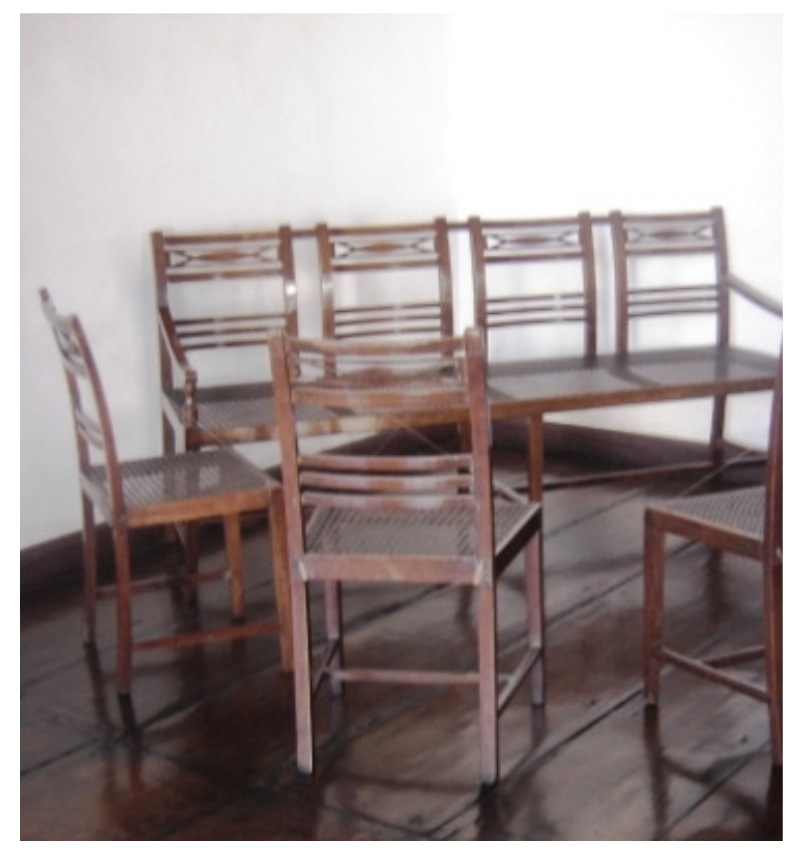

FIGURA 05 - Conjunto de banco e cadeiras Sheraton Brasileiro. Casa dos Contos, Ouro Preto. Fotografia da autora.

FIGURA 06 - Lavabo em pedra-sabão

(atribuído a Antônio Francisco Lisboa) e bancos em jacarandá. Sacristia da Igreja de Nossa Senhora do Carmo, Ouro Preto. Fonte: OLIVEIRA, M.R.A.; SANTOS FILHO, O.R. e SANTOS, A.F.B. O Aleijadinho e sua oficina. Catálogo das Esculturas Devocionais. São Paulo: Capivara, 2002, p.15. Fotografia de Henry You.

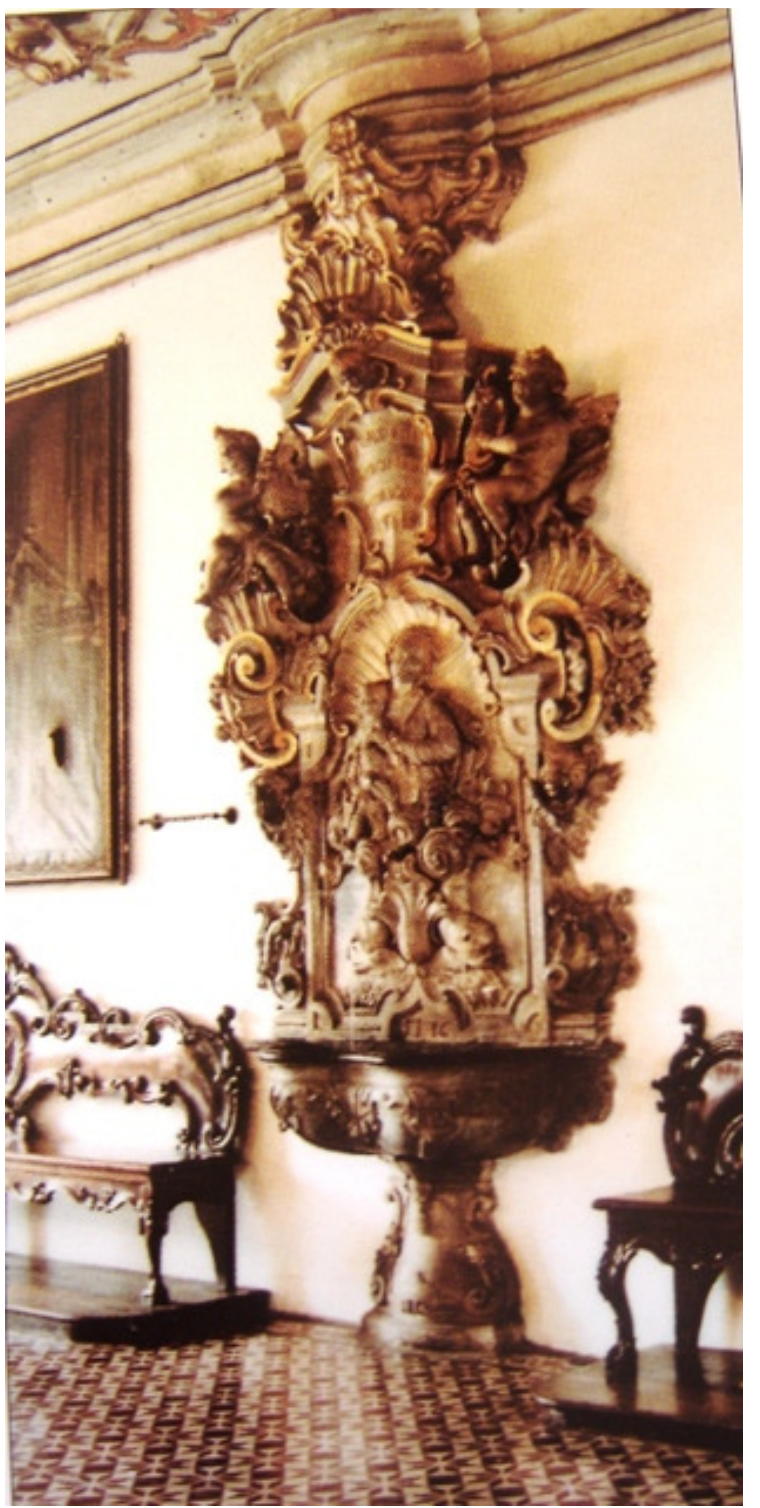




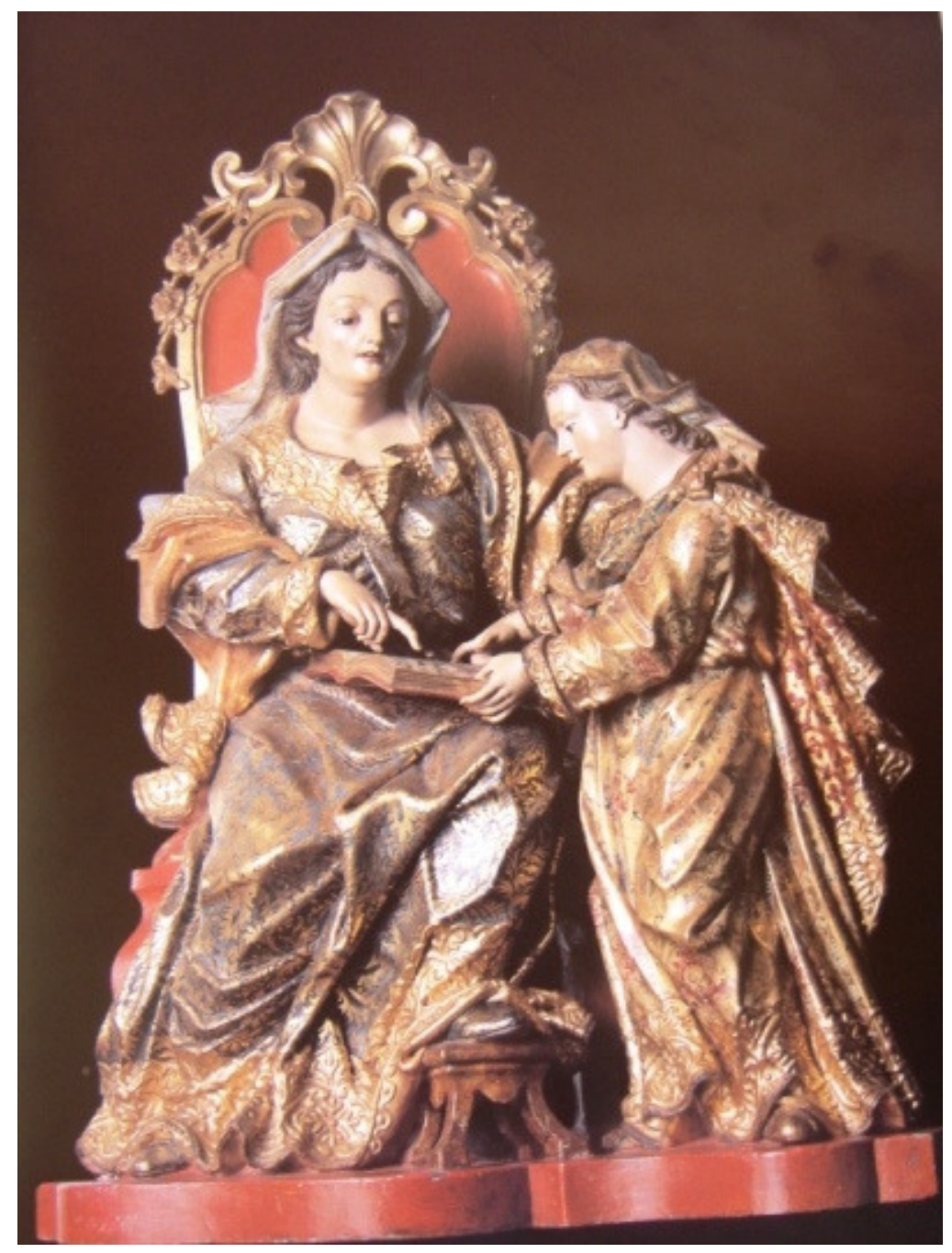

FIGURA 07 - Santana Mestra. 1775-79. Antônio Francisco Lisboa. (atr.) Madeira dourada e policromada. $94 \times 60 \times 44$. Museu do Ouro, Sabará. Fonte: OLIVEIRA, M.R.A.; SANTOS FILHO, O.R. e SANTOS, A.F.B. O Aleijadinho e sua oficina. Catálogo das Esculturas Devocionais. São Paulo: Capivara, 2002, p.71. Fotografia de Henry You.

\section{Notas}

(1) Ver, por exemplo, Witold Rybczynski, Casa, 1999. Riccardo Montenegro, Guia de história do mobiliário, 1995. Edward Lucie-Smith, Furniture,1997.

(2) Por isso, durante os últimos dias, em todas as paróquias tanto as catacumbas como as sacristias e os corredores de comunicação ficam apinhados de penitentes de pé, agrupados em torno dos confessores sentados em banquinhos ou outros assentos improvisados. [...] Mais à direita, senhoras da classe abastada estão sentadas nos degraus de um altar lateral [...] Senhoras de todas as classes, mantém-se sentadas no chão da igreja, em grupos, na posição em geral adotada pelas brasileiras nesse recinto sagrado". [Sem grifo no original], Jean Baptiste Debret, Viagem pitoresca e histórica ao Brasil, 1978. p. 261-264.

(3) Tais conclusões parciais foram extraídas da análise dos seguintes documentos: Inventário de Alfaias de Igrejas de 1855. Em Livros diversos, armário VII, prateleira 5. Inventário dos Ornamentos e mais bens que vieram de Lisboa para esta Cathedral de Mariana [...], 1749. Inventários de Mariana 1749-1869. Arquivo Eclesiástico da Arquidiocese de Mariana. 
(4) cf. José Wasth Rodrigues, Mobiliário, 1968. p. 109-110. Clado Ribeiro de Lessa (1906-1960), historiador do âmbito do IHGB, estudioso da obra de Varnhagen (Formação de Varnhagen, 1945). José de Almeida Santos foi um importante estudioso do mobiliário brasileiro. Publicou nos anos 1940 seu Mobiliário artístico brasileiro, em três tomos - o primeiro tomo tratava de uma história propriamente do móvel no Brasil, como veremos, o segundo e terceiro tomos constituíam um Dicionário de terminologia ebanística-; em 1950, publicou o Manual do colecionador brasileiro. Gustavo Barroso foi diretor do Museu Histórico Nacional do Rio de Janeiro desde o reconhecimento pelo Congresso Nacional em 1922, até sua morte em 1959. Barroso, cearense de nascimento, foi advogado, escritor, jornalista, teatrólogo e membro da Academia Brasileira de Letras. Publicou centenas de livros.

(5) Cf. FREYRE, Gilberto. Casa grande e senzala. São Paulo: Círculo do Livro, 1987, p. 234.

(6) O pai chamava-se Julien, o filho, continuador de sua obra Francisco Manuel. Ambos radicados em Pernambuco. Julien Béranger, mestre marceneiro francês, instalou sua oficina em Recife, em 1826, e formou um grupo de artesãos locais. Usando o jacarandá, procurou criar móveis “tipicamente" brasileiros ao entalhar temas inspirados na flora e fauna brasileiras em estillo neo-rococó, no entanto, com linhas inspiradas no estilo Império. Seus entalhes, ainda que com motivos naturalistas inspirados na flora nativa, eram combinados com um repertório tradicional, cornucópias, por exemplo. Aplicava um polimento uniforme e brilhante, tendo introduzido no Brasil o verniz de boneca. Julien morreu em 1853, e seu filho Francisco o sucedeu: pintor, desenhista e entalhador, aperfeiçoou-se em Paris e continuou o estilo do pai. Os móveis béranger foram copiados por outros artesãos em diferentes lugares do Nordeste. Ver Tilde Canti, O móvel do século XIX no Brasil, 1989.

\section{Referências bibliográficas}

ANDRADE, Rodrigo M. F. de. Introdução. In: RODRIGUES, José Wasth. Mobiliário. Rio de Janeiro: Ediouro, 1968. Não paginado. (As artes plásticas no Brasil).

ARQUITETURA Civil III: Mobiliário e Alfaias. São Paulo: FAU-USP, 1975. p. 159-160

CANTI, Tilde. O móvel no Brasil: origens, evolução e características. Rio de Janeiro: Agir, 1980.

CANTI, Tilde. O móvel do século XIX no Brasil. Rio de Janeiro: Cândido Guinle de Paula Machado, 1989.

CASCUDO, Câmara. Rede de dormir, uma pesquisa etnográfica. Rio de Janeiro: Global, 2003.

COSTA, Lúcio. Notas sobre a evolução do mobiliário luso-brasileiro. In: CAVALCANTI, Lauro. (Org). Modernistas na repartição. Rio de Janeiro: UFRJ; Minc/IPHAN, 2000. p. 195-206.

DEBRET, Jean Baptiste. Viagem pitoresca e histórica ao Brasil. Tomo II. Belo Horizonte: Itatiaia; São Paulo: Edusp, 1978.

DIAS, Hélcia. O mobiliário dos inconfidentes. Revista do Patrimônio Histórico e Artístico Nacional, n. 3, p 163172, 1939. Disponível em: <http://revista.iphan.gov.br/Revista\%20do\%20patrimonio-2.htm>.

FREYRE, Gilberto. Casa grande e senzala. São Paulo: Círculo do Livro, 1987. 
LUCIE-SMITH, Edward. Furniture: a concise history. London: Thames \& Hudson,1997.

MONTENEGRO, Riccardo. Guia de história do mobiliário - Os estilos de mobiliário do renascimento aos anos cinqüenta. Lisboa: Presença, 1995.

O MÓVEL da Casa Brasileira. São Paulo: Museu da Casa Brasileira, 1997.

OLIVEIRA, Myriam Andrade Ribeiro de. O rococó religioso no Brasil e seus antecedentes europeus. São Paulo: Cosac \& Naify, 2003.

OLIVEIRA, M.R.A.; SANTOS FILHO, O.R. SANTOS, A.F.B. O Aleijadinho e sua oficina. Catálogo das Esculturas Devocionais. São Paulo: Capivara, 2002.

PONTUAL, Roberto. Dicionário de Artes Plásticas no Brasil. Rio de Janeiro: Civilização Brasileira, 1969.

RODRIGUES, José Wasth. Documentário arquitetônico relativo à antiga construção civil no Brasil. São Paulo: Edusp; Martins, 1975.

RODRIGUES, José Wasth. Mobiliário. Rio de Janeiro: Ediouro, 1968. (As artes plásticas no Brasil).

RYBCZYNSKI, Witold. Casa: pequena história de uma idéia. Rio de Janeiro: Record, 1999.

SANTOS, José de Almeida. Manual do colecionador brasileiro. São Paulo: Livraria Martins Editora, 1950. 334 p.

SANTOS, José de Almeida. Mobiliário artístico brasileiro. São Paulo: Elvino Pocai, 1944.

SANTOS, Maria Cecília Loschiavo dos. Móvel moderno no Brasil. São Paulo: Edusp, 1995.

SMITH, Robert. Igrejas, casas e móveis. Aspectos da arte colonial brasileira. Recife: Universidade Federal de Pernambuco, 1979.

VERÍSSIMO, Francisco Salvador; BITTAR, William Seba Mallmann. 500 anos da casa no Brasil. Rio de Janeiro: Ediouro, 1999.

\section{Crédito}

* Doutora em História da Arte: Historiografia, Metodologia e Conservação do Patrimônio pela Universidade de Granada - Espanha; Pós-Doutorado no Departamento de História da Arte e Estética do Projeto da Faculdade de Arquitetura de Urbanismo da Universidade de São Paulo - FAU-USP. Professora-Adjunta de História da Arte no Departamento de Artes e Design do Instituto de Artes e Design da Universidade Federal de Juiz de Fora - MG; Professora Colaboradora do Mestrado de História do Instituto de Ciências Humanas da Universidade Federal de Juiz de Fora - MG.

e-mail: brandaoangela@hotmail.com 